\title{
ABSCESSOS CEREBRAIS MÚLTIPLOS
}

\author{
A PROPOSITO DE DOIS CASOS
}

SANDRO L. ROSSITTI* - JOĀO FLAVIO M. ARAUJO* - ROQUE J. BALBO**

\begin{abstract}
RESUMO - Os autores sumariam os conceitos vigentes sobre a patogênese e a cirurgia dos abscessos cerebrais múltiplos e relatam sua experiência recente em dois casos, com acompanhamento por tomografia computadorizada.
\end{abstract}

Multiple brain abscesses: report of two cases.

SUMMARY - The authors summarize the current concepts regarding pathogenesis and surgical management of multiple brain abscesses, and report their experience with two recent cases with computerized tomographic follow-up.

A maioria das infecções que envolvem o sistema nervoso são secundárias a infecção de outras partes do organismo, penetrando os microrganismos por extensão local de estruturas vizinhas ou pela corrente sanguínea ou ainda por implantaçāo direta nos ferimentos penetrantes e atos operatórios. Abscesso cerebral é um foco circunscrito de supuração intraparenquimatosa, em geral de origem bacteriana. É provavelmente precedido de embolia ou de tromboflebite, pois o tecido nervoso sadio é resistente à supuraçāo e abscessos experimentais sāo obtidos apenas pela injeção de meio de cultura infectado ou injeçāo de microrganismos virulentos em áreas encefálicas previamente necrosadas. Abscessos cerebrais múltiplos são raros, exceto quando se originam por disseminação hematogênica de uma fonte primária, em geral infecção pulmonar, endocardite bacteriana ou bacteremia de qualquer origem na presença de cardiopatia congênita com "shunt" da direita para a esquerda. Săo mais frequentes no território distal das artérias cerebrais médias. Fatores predisponentes sāo as infecções pulmonares crônicas, as cardiopatias congênitas cianóticas e os estados de deficiência imunitária. $\mathrm{Na}$ formação do abscesso encontramos diferentes estágios evolutivos. Estudos experimentais e clinicos 1 permitem reconhecer 4 fases distintas: cerebrite precoce (de um a três dias), cerebrite tardia (de 4 a 9 dias), encapsulamento precoce (de 11 a 13 dias) e encapsulamento tardio (após 14 dias). $\mathrm{O}$ abscesso se expande gradativamente, destruindo e comprimindo o tecido nervoso à medida em que cresce, resultando em morte por herniação (cone de pressão temporal ou cerebelar) ou por ventriculite e meningite graves quando se rompe para o sistema ventricular ou espaço subaracnóideo. E importante acentuar que a maioria dos abscessos cerebrais se comporta como processos expansivos e evidências clinicas de infecção, como febre e sinais de irritação meníngea, podem estar ausentes. $O$ tratamento das supurações intracranianas foi uma das primeiras preocupaçōes da moderna neurocirurgia. Em 1876, Sir William Macewen diagnosticou pela primeira vez um abscesso cerebral em um paciente e lhe foi negada permissão para operá-lo. Sua hipótese confirmou-se na necrópsia. A primeira drenagem aberta de abscesso cerebral foi realizada por Macewen em 1881 e essa tornou-se a técnica de escolha por muitos anos. Da drenagem simples desenvolveu-se a marsupialização, pela qual através de pequena craniotomia ressecava-se o tecido cerebral sobre o abcesso, sendo sua cápsula suturada à duramáter e sua cavidade preenchida com pequenas gazes que eram extrudidas uma a uma pela pressão intra-craniana. A aspiração por agulha era recomendada por Dandy (1926). Clovis Vincent (1936) propôs a extirpação completa da lesão com seu conteúdo integro. $O$ afastamento da drenagem aberta $e$, posteriormente, a introdução de meios radiodiagnósticos mais precisos e dos antibióticos reduziu consideravelmente a mortalidade e morbidade. A despeito dos avanços na tecnologia diagnóstica e terapêutica das últimas duas décadas, a conduta face

Trabalho do Departamento de Neuropsiquiatria (Setor de Neurocirurgia), Faculdade de Ciências Médicas da Pontifícia Universidade Católica de Campinas (PUCCAMP) e do Departamento de Neurocirurgia do Hospital Vera Cruz, Campinas: * Médico Residente; ** Professor Adjunto.

Hospital Vera Cruz (Departamento de Neurocimurgia) - Avenida Andrade Neves $402-1.9100$ Campinas $S P$ - Brasil 
aos abscessos cerebrais é ainda bastante controversa com relação a técnica operatória ideal, seleçăo e duraçăo da terapia antimicrobiana e uso de corticosteróides, além da crescente quantidade de relatos de sucessos com a conduta exclusivamente clínica 3 .

E nosso propósito relatar a experiência observada em dois casos recentes de abscessos cerebrais múltiplos submetidos a cirurgia (punção e aspiração), com acompanhamento tomográfico computadorizado.

\section{OBSERVAÇŌES}

Caso 1 - M.L.S., paciente do sexo feminino, com 7 anos de idade, branca, brasileira, registro hospitalar 258.993.5 (HMCP). Relata a mãe da paciente que esta vinha se queixando há dois meses de forte cefaléia frontal e retro-ocular, com fotofobia, astenia e inapetência progressivas. Há um mês apresentou crise convulsiva sensitivo-motora no hemicorpo esquerdo, com duração de alguns minutos. Vômitos incoercíveis há três dias. Internada em nosso Serviço em 29-03-87, após passagem pelo pronto-socorro, com moderado torpor, hemiparesia esquerda e edema de papila bilateral à fundoscopia. Angiografia carotídea bilateral (30-03-87) mostrou-se compatível a processo expansivo avascular fronto-parietal direito. Tomografia computadorizada (CT) do encéfalo (01-04-87) mostrou extensa área de menor atenuação no hemisfério cerebral direito e acentuado desvio do sistema ventricular supratentorial para 0 lado oposto; após injeção endovenosa de contraste iodado destacaram-se lesões nodulares, em número de quatro, com halo de impregnação periférica. (Fig. 1 A,B). Com a hipótese diagnóstica de abscessos cerebrais múltiplos, foi iniciada imediatamente terapia endovenosa com metronidazol. Craniotomia fronto-parieto-temporal direita (02-04-87) revelou tecido cerebral bastante edemaciado: foram puncionados e aspirados três grandes abscessos, sendo as respectivas cavidades lavadas com gentamicina em solução salina. Dado o acentuado edema cerebral, não foi suturada a duramáter nem recolocado o retalho ósseo.

Mantida sob hiperventilaçăo controlada por três dias, ao final dos quais encontrava-se alerta e orientada, com hemiparesia esquerda de predomínio braquial. Recebeu $6 \mathrm{mg}$ de dexametasona ao dia, em doses fracionadas, por 10 dias. Cultura do material purulento revelou Staphylococcus aureus. Mantida terapia com metronidazol por 10 dias e, a seguir, iniciada terapia com ceftriaxona e cloranfenicol. Duraplastia em 16-04-87 com enxerto de material homólogo, não sendo ainda possível realizar cranioplastia. Em 28-04-87 a criança encontrava-se afebril, ativa e com hemiparesia esquerda em franca regressão, sendo suspensa a antibioticoterapia. CT de controle (29-04-87) revelou abscesso único em região fronto-parietal direita com discreto efeito de massa (Fig. 1 C). Em 04-04-87 realizamos punção e aspiração percutânea do abscesso remanescente, sendo sua cavidade lavada com gentamicina em soluçāo salina. No mesmo dia foi iniciada terapia endovenosa com mefoxin, mantida por 10 dias. Cultura negativa. O quadro neurológico manteve-se inalterado. CT de controle (21-05-87) revelou persistência de abscesso único na região fronto-parietal direita, sendo realizada nova punção e aspiração percutânea em 02-04-87. Cultura negativa. Alta hospitalar em 06-06-87, apresentando discreto déficit motor e hiperreflexia tendinosa no dimídio esquerdo. CT de controle (06-07-87) revelou cavidade hipodensa na projeçāo do abscesso localizado no exame anterior e discreta dilatação do ventrículo lateral direito (Fig. 1 D). Em seu último retorno (28-08-87) apresentava apenas assimetria de reflexos tendinosos e leve palidez das papilas ópticas à fundoscopia. Deve ser reinternada para cranioplastia.

Caso 2 - P.R., paciente do sexo feminino, com 60 dias de idade, branca, brasileira, registro hospitalar N-205.87 (HVC). Internada no Serviço de Neonatologia em 30-05-87 com meningite pneumocócica e crises convulsivas sub-entrantes, tendo recebido assistência ventilatória, terapia antibiótica (penicilina cristalina, no segundo dia substituída por cefotaxina) e anticonvulsiva (fenitoina e tionembutal). Evoluiu com síndrome de secreção inapropriada do hormônio antidiurético. Avaliada em 04-06-87, apresentando-se torporosa, sem sinais de lateralização, com pesquisa de coleção subdural positiva à esquerda (bacterioscopia e cultura negativas). CT (09-06-87) mostrou área extensa de menor atenuacão em hemisfério cerebral direito, com pequeno desvio do sistema ventricular para o lado oposto; após injeção de contraste iodado endovenoso destacaram-se duas lesões nodulares de projeção têmporo-parietal direita (Fig. 2 A). Mantida terapia clínica até 12-06-87, quando foi submetida a trepanação parieto-temporal direita, sendo puncionado um único abscesso e drenados três $\mathrm{ml}$ de material purulento. Bacterioscopia e cuitura foram negativos. CT de controle (18-06-87) mostrou o processo encefalítico em involução (Fig. 2 B). A antibioticoterapia foi mantida até 22-06-87, tendo a paciente alta hospitalar em 24-06-87 em bom estado geral, sem sequiela neurológica aparente ao exame neurológico tradicional. Em seu áltimo retorno (28-08-87) apresentava-se ativa, sem sinais de lateralização, com fundoscopia normal em ambos os olhos. 

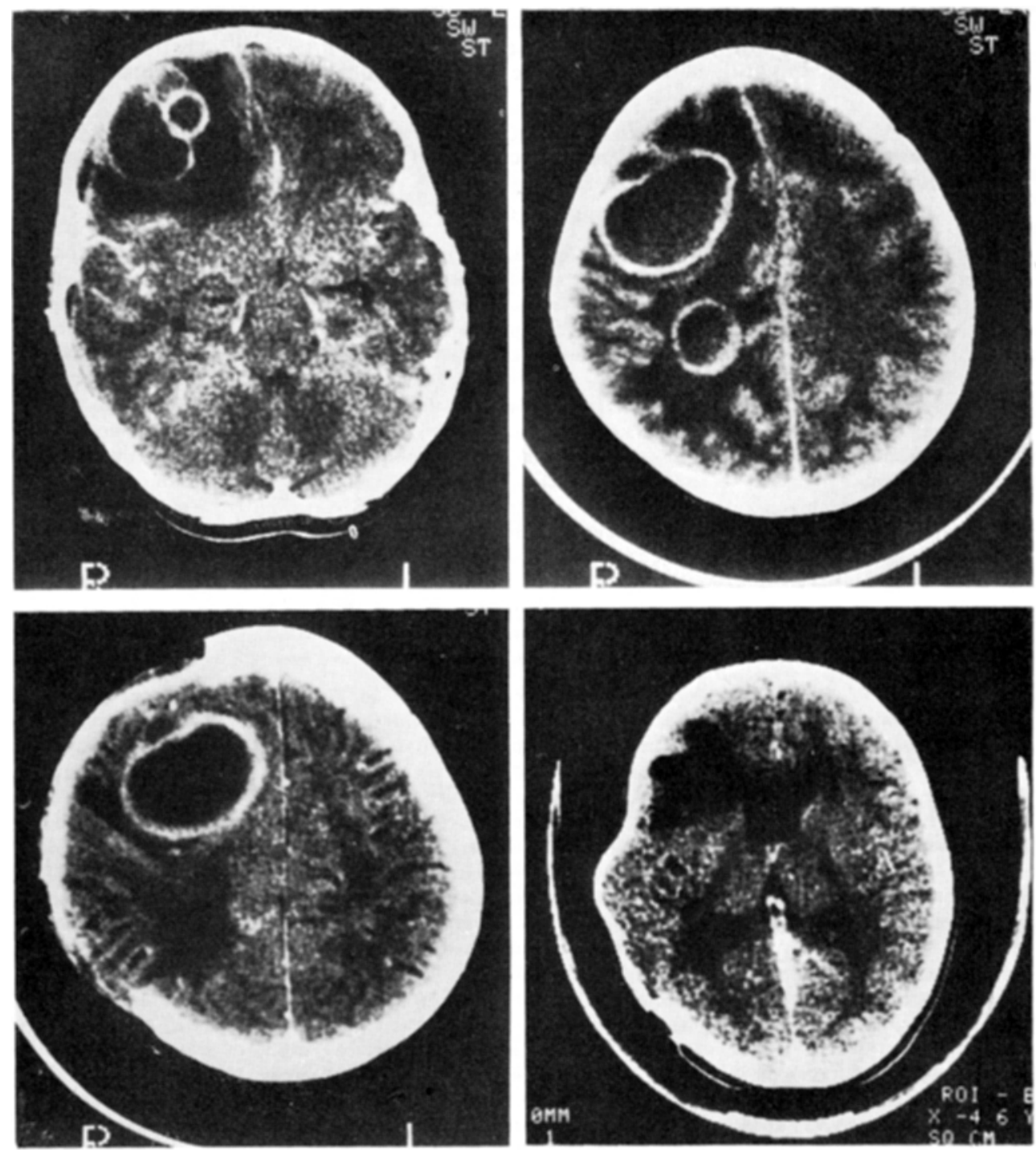

Fig. 1 - Caso 1. Tomografia computadorizada: no alto (A e B), em 01/04/87; em baixo, à esquerda (C) em 29/04/87 e à direita (D) em 06/0\%/87.

\section{COMENTARIOS}

A abordagem dos abscessos cerebrais pode variar muito de caso para caso, na dependência do número e localização das lesōes, do estágio evolutivo, do agente etiológico e do estado geral do paciente. O diagnóstico errôneo ou tardio, a difjculdade de localização do processo no campo operatório e intervençōes demasiado precoces (na fase de cerebrite) contribuiram para a alta mortalidade dos abscessos cerebrais, em particular dos abscessos múltiplos, antes do advento da CT. A tomografia seriada permite a identificação precoce e a localização exata da lesão, determina o melhor momento para a cirurgia e facilita o diagnóstico mais rápido das complicaçōes pós-operatórias 2 . A imagem tomográfica de uma lesão de baixa densidade, com halo hipercaptante e edema adjacente, é muito sugestiva de abscesso (em especial se a lesão for multiloculada ou múltipla), mas não exclui a possibilidade de se tratar de gliomas, metástases cerebrais, ou áreas de infarto, doenças aliás muito mais frequentes que os abscessos cerebrais 2,3 . 

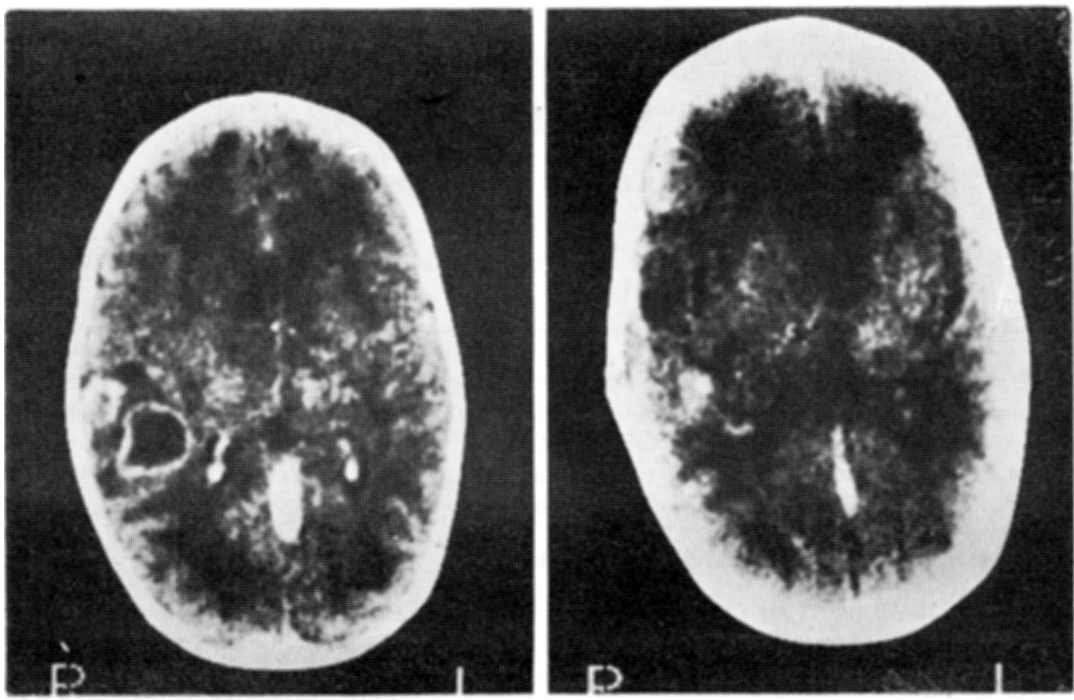

Fig. 2 - Caso \&. Tomografia computadorizada: d direita (A) em. 09/06/87, à esquerda (B) em 18/06/87.

Recomendamos que a cirurgia seja realizada para terapia de todo abscesso cerebral presumido, tão logo a lesăo esteja encapsulada. A cirurgia permite não apenas descompressão mais rápida do tecido nervoso e redução do período de antibioticoterapia, como confirma o diagnóstico. É universalmente aceito, que os abscessos requerem tratamento cirúrgico. Já a técnica operatória a ser empregada é tema de grande discussão. A drenagem por agulha inserida através de trepanação ou de craniotomia, seguida de lavagem com solução de antibiótico, tem a vantagem de evitar a manipulação e ressecção de tecido cerebral edemaciado porém viável. Essa técnica é particularmente adequada para lesões em estruturas profundas ou nas proximidades de áreas motoras ou de linguagem e tem ainda a vantagem de ser facilmente repetida, se necessário. A excisão primária via craniotomia é indicada para lesōes bem encapsuladas, em áreas silentes do encéfalo. $O$ risco de ruptura do abscesso durante a dissecção pode ser prevenjdo pela punção e aspiraçāo prévia do seu conteúdo. Mesmo assim, representa risco adicional para a vida do paciente, e aumenta a possibilidade de sequelas neurológicas.

Iniciamos a antibioticoterapia algumas horas antes da cirurgia, com agentes de amplo espectro bactericida, modificando-a se necessário após a bacterioscopia e cultura do material purulento, senđo mantida em geral até duas semanas após a cirurgia. Empregamos corticosteróides e manitol para diminuir o efeito de massa, responsável por déficit neurológico importante e possível herniação.

Areas de cerebrite devem ser tratadas de modo conservador. Nesses casos e nos abscessos bem formados em que a cirurgia estiver contraindicada, como nas diáteses hemorrágicas, o acompanhamento tomográfico deve ser mais frequente, e o neurocirurgião deve estar preparado para intervir ao primeiro sinal de insucesso clínico.

\section{REFERENCIAS}

1. Britt RH, Enzmann DR - Clinical stages of human brain abscesses on serial CT scans after contrast infusion: computerized tomographic, neuropathological, and clinical correlations. J Neurosurg $59: 972,1983$.

2. RosenbIum ML, Hoff JT, Norman D, Weinstein PR, Pitts L - Decreased mortality from brain abscess since advent of computerized tomography. $J$ Neurosurg 49:658, 1978.

3. Rosenblum ML, Mampalam TJ, Pons VG - Controversies in the management of brain abscesses, Clin Neurosurg $33: 603,1986$. 